\title{
Recommendations on screening for depression in adults
}

\author{
Canadian Task Force on Preventive Health Care
}

See related commentary by Bland and Streiner on page 753 and at www.cmaj.ca/lookup/doi/10.1503/cmaj.130634

$\mathrm{D}$ epression is a mood disorder that affects the way a person feels, thinks or behaves, which may impair social or occupational functioning. ${ }^{1}$ The onset of depression can be triggered by biological, psychosocial or environmental factors, such as traumatic life events. Those who experience an episode of depression are at increased risk of experiencing future episodes. Major depression is characterized by 1 or more major depressive episodes. ${ }^{1} \mathrm{~A}$ major depressive episode is defined by the presence of 5 or more of 9 key symptoms of depression during a 2-week period and a change from previous functioning (Box 1). ${ }^{2}$

The 2002 Canadian Community Health Survey reported that 1 in every 8 adults met the criteria for major depression at some point during their lifetime and that 1 in every 20 individuals aged 15 or older met the criteria in the past 12 months. ${ }^{1}$ In 2005, the 1-year incidence of major depressive disorder was estimated at 3\% (1 in every 30 Canadians was newly diagnosed with depression in a 1-year period). ${ }^{3}$ (See Box 2 for definitions of screening, incidence and prevalence.)

Certain subgroups of the population have a higher prevalence of depression than others. There is a strong association between some chronic medical conditions (with or without pain) and an increased prevalence of major depression. ${ }^{4}$ Major depression is also more common among people of Aboriginal origin, ${ }^{5}$ women during the postpartum period ${ }^{6}$ and people with a history of substance abuse. ${ }^{7}$

Long-term consequences of depression include reduced quality of life, risk of suicide, ${ }^{8}$ increased rates of hospital admission, stigmatization $^{1}$ and increased risk of chronic physical conditions. ${ }^{9}$ Major depression is among the leading causes of disability-adjusted life-years worldwide. ${ }^{10}$ In addition, the economic burden of depression is considerable: in Canada alone, the estimated annual productivity losses owing to depression were $\$ 4.5$ billion in 1998. ${ }^{.1}$

Because depression is potentially treatable, there has been interest in screening patients who present to primary care settings. However, guide- lines on screening for depression differ between countries. The US Preventive Services Task Force recommends universal screening where supports are in place to ensure appropriate follow-up. ${ }^{12}$ The UK National Institutes for Health and Clinical Excellence recommends targeted case identification (people with a history of depression or with current chronic physical health problems and associated functional impairment, or both) rather than general population screening. ${ }^{13}$

This document updates the 2005 Canadian Task Force on Preventive Health Care guideline, which recommended screening for depression in adults in primary care settings with both feedback to the clinician regarding depression status and a system for managing treatment (antidepressant medications and psychotherapeutic interventions)..$^{14}$ The absence of current Canadian recommendations, the high prevalence of major depression in the Canadian population and the difference in recommendations between countries were the basis for revisiting this topic. This update was produced using the revised methodology of the task force and is based on current evidence of the harms and benefits of screening for depression.

\section{KEY POINTS}

- The systematic review for this guideline did not identify high-quality evidence of the effectiveness of screening for depression.

- Although the systematic review did not identify direct evidence of the harms of screening, we remain concerned about false-positive diagnoses with unnecessary treatment.

- For adults with no apparent symptoms of depression, who are at average risk of depression or who may be at increased risk of depression, we recommend not routinely screening for depression in primary care settings.

- Clinicians should be alert to the possibility of depression, especially in patients with characteristics that may increase their risk of depression, and should look for it when there are clinical clues, such as insomnia, low mood, anhedonia and suicidal thoughts.

- Randomized controlled trials with an unscreened control group that evaluate the effect of screening for depression on clinically relevant outcomes should be a high research priority, especially in populations at increased risk of depression. 


\section{Methods}

The Canadian Task Force on Preventive Health Care is an independent panel of clinicians and methodologists that makes recommendations about clinical manoeuvres aimed at primary and secondary prevention (www.canadiantaskforce.ca). Work on each set of recommendations is led by a workgroup of 2 to 6 members of the task force. Each workgroup establishes the research questions and analytical framework for the guideline.

The current work was led by a workgroup of 6 members of the task force, supported by scientific staff at the Public Health Agency of Canada and the University of Alberta (members of the guideline writing group are listed at the end of the article). The research questions and analytical framework for this guideline (available in Appendix 1) were incorporated into the search protocol. The task force chose to focus on clinically relevant outcomes: quality of life, rates of suicidality (attempts or ideation), all-cause mortality, depression-related mortality, rates of hospital admission and changes in symptoms of depression (treatment response or remission).

The recommendations were revised and approved by the entire task force and underwent external review by experts in the field and by stakeholders. Details about the task force's

\section{Box 1: Definition of a major depressive episode according} to DSM-IV-TR criteria ${ }^{2}$

A major depressive episode is defined by the presence of 5 or more of the following 9 key symptoms of depression during a 2 -week period and a change from previous functioning. At least 1 of the symptoms is either depressed mood or loss of interest. ${ }^{2}$

- Depressed mood most of the day, nearly every day, as indicated either by subjective report (e.g., feels sad or empty) or observations made by others (e.g., appears tearful).

- Markedly diminished interest or pleasure in all, or almost all, activities most of the day, nearly every day (as indicated either by subjective account or observation made by others).

- Significant weight loss when not dieting or weight gain (e.g., a change of more than $5 \%$ of body weight in a month), or decrease or increase in appetite nearly every day.

- Insomnia or hypersomnia nearly every day.

- Psychomotor agitation or retardation nearly every day (observable by others, not merely subjective feelings of restlessness or being slowed down).

- Fatigue or loss of energy nearly every day.

- Feeling of worthlessness or excessive or inappropriate guilt (which may be delusional) nearly every day (not merely self-reproach or guilt about being sick).

- Diminished ability to think or concentrate, or indecisiveness, nearly every day (either by subjective account or as observed by others).

- Recurrent thoughts of death (not just fear of dying), recurrent suicidal ideation without a specific plan, or a suicide attempt or specific plan for committing suicide.

Note: DSM-IV-TR = Diagnostic and Statistical Manual of Mental Disorders, Fourth Edition, Text Revision. ${ }^{2}$ methods can be found elsewhere. ${ }^{15,16}$ The systematic review on which the recommendations are based was performed independently by the Evidence Review and Synthesis Centre at McMaster University. ${ }^{17}$ The review was performed according to the final, peer-reviewed protocol (available at http://canadiantaskforce.ca/wp-content/uploads /2012/12/Proposal-Screening-for-Depression120312_FINAL_2.pdf?9d7bd4). The task force used the Grading of Recommendations Assessment, Development and Evaluation (GRADE) system $^{18}$ to determine the quality of evidence and strength of recommendations (Box 3).

\section{Recommendations}

A summary of the recommendations for clinicians and policy-makers is shown in Box 4 and Appendix 2. More detailed explanations of the evidence base of the recommendations are available in Appendix 3.

\section{Adults at average risk}

For adults at average risk of depression, we recommend not routinely screening for depression. (Weak recommendation; very-low-quality evidence.)

The systematic review for this guideline did not find any studies evaluating the benefits of screening the average-risk population for depression in primary care settings. ${ }^{17}$ The review found 5 quasi-experimental studies (before-after design with a nonrandomized control group) that examined the effect of community-based screening for depression on suicide rates among people aged 65 and older (Table 1). ${ }^{19-23}$ These 5 studies were conducted in Japanese rural regions with suicide rates that ranged from 49.6 to 418.4 per 100000 among women and 113 to 326 per 100000 among men. All of the studies showed a statistically significant reduction in the number of completed suicides after implementation of the program (relative risk reduction $0.51,95 \%$ confidence interval 0.34-0.75). However, these studies have several important methodological limitations that compromise their internal validity. For example, it is uncertain what portion of

\section{Box 2: Defining incidence and prevalence}

- By definition, screening is used to identify only new cases of depression. Screening does not apply to patients who are known to have depression, have a history of depression or are receiving treatment for depression.

- "Incidence" refers to new cases of depression. "Prevalence" refers to the presence of depression during a specified period regardless of when the episode began; it includes new, recurrent and chronic cases. 
the reported outcomes involved people who actually received the intervention. The number of reported suicides (before and after the intervention) was based on independent statistics reported by the local health agency, not a followup of people who were screened. Also, because of the community-based nature of the intervention, there is a particularly high risk of bias, because the people classifying the deaths as suicides were not blinded to the group assignments. Given that the studies compared a small number of suicides in both the intervention and control groups, any influence on even a few classifications could have affected the results.

Further, the generalizability of these results to the Canadian population is uncertain given that the prevalence of depression among older people living in the rural Japanese communities is 5 times higher than the prevalence among older Canadians as a whole $(10.4 \%$ v. $2 \%),{ }^{19,20}$ and the suicide rate among elderly Japanese women is more than 7 times higher than the rate among comparably aged Canadian women (23.4 v. 3.3 per 100000 among women aged 75-84 yr). ${ }^{21}$ Other factors that limit the applicability of these results are the cultural and social differences between Canada and Japan.

Previous reviews ${ }^{22,23}$ included multiple studies in which both the treatment and control groups were screened, with only the former receiving treatment if depression was found (Appendices 4 and 5). Rather than studying the effect of screening per se, such studies actually compared the addition of treatment to screening alone. In addition, screening all participants may increase awareness of depressive symptoms, which can either overestimate or underestimate any benefits. If participants in the control group are more aware of their symptoms, they may present themselves as more depressed, inflating apparent differences between groups. If, on the other hand, screening leads participants in the control group to engage in some form of treatment (this could be as simple as exercise or self-care), the apparent differences between the 2 groups may be reduced.

The systematic review for the current guideline did not identify any eligible studies measuring the harms of screening for depression. Potential harms of screening include false-positive diagnoses, with subsequent unnecessary treatment; adverse effects of medical therapy among people correctly identified as having depression; ${ }^{24}$ and the consequences of labelling and stigma. ${ }^{4}$

By definition, any health benefits of screening would accrue among newly identified cases of depression (not among patients who are known to have depression or are receiving treatment).
Detecting new cases of depression and treating patients identified as having depression is a desired outcome of screening but does not constitute a health benefit by itself. The net benefit of screening would depend on earlier identification and successful treatment and would require that the benefits of such treatment outweigh any harms, such as adverse effects of medications.

\section{Box 3: Grading of recommendations}

- Recommendations are graded according to the Grading of Recommendations Assessment, Development and Evaluation (GRADE) system. ${ }^{18}$ GRADE offers 2 strengths of recommendation: strong and weak. The strength of recommendations is based on the quality of supporting evidence, the degree of uncertainty about the balance between desirable and undesirable effects, the degree of uncertainty or variability in values and preferences, and the degree of uncertainty about whether the intervention represents a wise use of resources.

- Strong recommendations are those for which the task force is confident that the desirable effects of an intervention outweigh its undesirable effects (strong recommendation for an intervention) or that the undesirable effects of an intervention outweigh its desirable effects (strong recommendation against an intervention). A strong recommendation implies that most people will be best served by the recommended course of action.

- Weak recommendations are those for which the desirable effects probably outweigh the undesirable effects (weak recommendation for an intervention) or undesirable effects probably outweigh the desirable effects (weak recommendation against an intervention) but appreciable uncertainty exists. A weak recommendation implies that most people would want the recommended course of action, but many would not. For clinicians, this means they must recognize that different choices will be appropriate for each individual, and they must help each person arrive at a management decision consistent with his or her own values and preferences. Policy-making will require substantial debate and involvement of various stakeholders. Weak recommendations result when the balance between desirable and undesirable effects is small, the quality of evidence is lower, or there is more variability in the values and preferences of patients.

- Evidence is graded as high, moderate, low or very low, based on how likely further research is to change our confidence in the estimate of effect.

The GRADE companion document to task force guidelines is available at www.canadiantaskforce .ca/docs/grade_ENG.pdf. Recent task force publications on the application of the GRADE methodology are available at http://canadiantaskforce.ca/guidelines/other-publications/

\section{Box 4: Summary of recommendations for clinicians and policy-makers}

Recommendations on screening for depression in primary care settings are provided for people 18 years of age or older who present at a primary care setting with no apparent symptoms of depression. These recommendations do not apply to people with known depression, with a history of depression or who are receiving treatment for depression.

- For adults at average risk of depression, * we recommend not routinely screening for depression. (Weak recommendation; very-low-quality evidence)

- For adults in subgroups of the population who may be at increased risk of depression, $\dagger$ we recommend not routinely screening for depression. $\neq$ (Weak recommendation; very-low-quality evidence)

*The average-risk population includes all individuals 18 years of age or older with no apparent symptoms of depression who are not considered to be at increased risk.

tSubgroups of the population who may be at increased risk of depression include people with a family history of depression, traumatic experiences as a child, recent traumatic life events, chronic health problems, substance misuse, perinatal and postpartum status, or Aboriginal origin.

$\neq$ Clinicians should be alert to the possibility of depression, especially in patients with characteristics that may increase the risk of depression, and should look for it when there are clinical clues, such as insomnia, low mood, anhedonia and suicidal thoughts. 


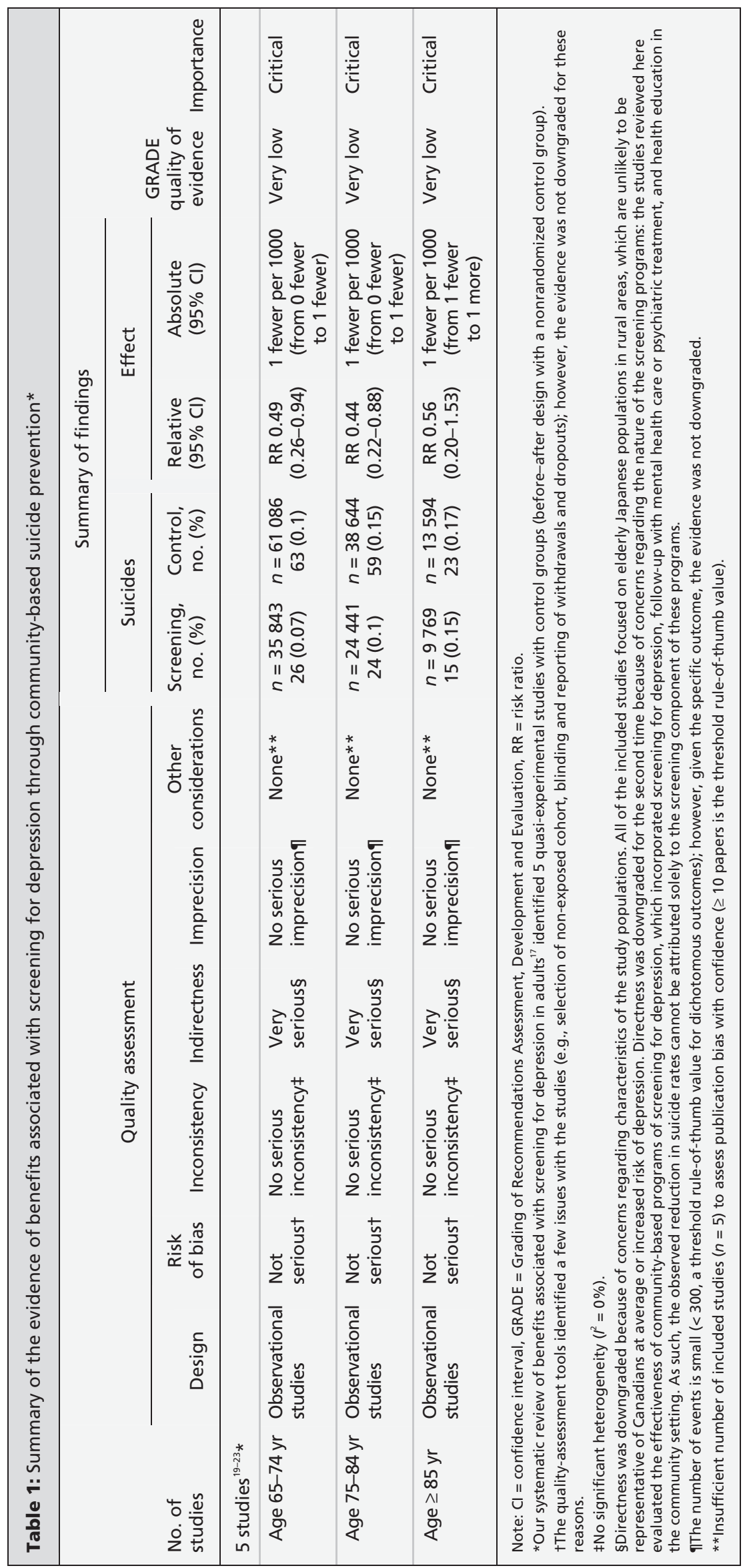


Weighing the likelihood of such a net benefit requires consideration of several factors. First, the effectiveness of screening tools in identifying new cases of depression (the objective of screening) is uncertain. ${ }^{25}$ Second, evidence shows that people with mild depression may not benefit from treatment, which suggests that some treatments triggered by screening are actually unnecessary. ${ }^{26,27}$ Third, some patients with diagnosed depression will decide not to accept treatment or will stop treatment prematurely, before remission, in which case screening will likely not lead to benefit. ${ }^{28,29}$ Given the lack of evidence for net benefit, the task force recommends against routine screening for depression in people at average risk in primary care settings.

This recommendation places a relatively high value on the importance of showing a clear net benefit before recommending routine screening for an entire population, and on the potential harms that may result from screening. The recommendation places a relatively low value on the unproven likelihood that early identification and subsequent treatment of depression may lead to better health outcomes. Physicians who believe that their patients (or a subset of their patients) place a high value on the potential benefits of screening for depression and are less concerned with the potential harms could reasonably choose to implement screening for depression in these patients.

\section{Adults at increased risk}

For adults in subgroups of the population who may be at increased risk of depression, we recommend not routinely screening for depression. (Weak recommendation; very-low-quality evidence.)

The incidence of depression (and prevalence of undetected depression) may be higher in populations at increased risk, which in theory would be expected to favourably influence the potential benefit of screening. However, the efficacy and adverse effects of treatment, the performance of screening tools and the possibility of harms likely also differ among subgroups of the population who may be at increased risk of depression. Therefore, one cannot assume that screening will benefit people at increased risk simply because they may have a higher incidence and prevalence of depression.

The systematic review for the current guideline did not identify any eligible studies showing benefits or harms of screening for depression in subgroups of the population at increased risk of depression. ${ }^{17}$ Subgroups that we considered as being at increased risk (based on the systematic review for the current guideline) included people with a family history of depression, traumatic experiences as a child, recent traumatic life events, chronic health problems, substance abuse, and perinatal or postpartum status. Given the lack of evidence for net benefit, the task force recommends against routine screening for depression in these groups at increased risk.

Factors influencing this recommendation were similar to those discussed in the preceding section for people at average risk. Physicians who believe that their patients (or a subset of their patients) place a high value on the potential benefits of screening for depression and are less concerned with the potential harms could reasonably choose to implement screening for depression in these patients.

\section{Considerations for implementation}

\section{Patients with clinical clues to depression}

Screening for depression refers to the detection of depression among patients with no apparent symptoms. Yet, clinicians can use symptoms of depression (e.g., insomnia, low mood, anhedonia and suicidal thoughts) to identify patients with potential depression. ${ }^{30}$ Evidence suggests that detecting depression based on clinical symptoms tends to identify patients with more severe depression, who may be more likely to benefit from treatment. ${ }^{31}$ Clinicians should be alert to the possibility of depression in patients with clinical clues, especially those at increased risk of depression, and implement treatment as appropriate when depression is diagnosed.

\section{Patient preferences}

Although there was high variability in patient preferences and values, patients generally consider screening for depression to be important and the screening tools to be acceptable. ${ }^{32,33}$ However, most studies of the acceptability of screening for depression that were identified in the systematic review focused on perinatal women. ${ }^{17}$ There was some evidence that any treatment in identified cases should be culturally sensitive and that matching treatment to patient preferences improves outcomes. ${ }^{34-37}$

\section{Resource implications}

Evidence from a modelling study in the United States suggested that one-time screening for depression may be cost-effective. ${ }^{38}$ However, this conclusion was based on a low-cost screening approach (maximum $\$ 6$ per person) and on high remission rates associated with treatment (settings that can achieve full remission in $45 \%$ of patients and partial remission in an additional 25\%). Given the lack of support for these assumptions, the validity of this conclusion is uncertain.

The time clinicians take to screen for depression reduces their availability to deliver other 
services of known clinical benefit (opportunity cost). Evidence from a Canadian modelling study suggests that routine screening to identify new cases of depression, resulting in increased rates of treatment, may not reduce the burden of depression. ${ }^{39}$ Instead, focusing efforts on reducing episodes of relapse (e.g., through long-term treatment in patients with known depression) may be a more efficient use of resources. ${ }^{39}$

\section{Integrated staff-assisted systems}

Integrated staff-assisted systems engage case managers, care support and coordination staff, or social workers, who play a central role in working with primary care physicians, mental health specialists and nurse practitioners to provide de- pression management and follow-up. Evidence suggests that such integrated systems may be more effective than usual care in increasing the likelihood of successful treatment of depression..$^{22}$ However, it is unclear whether screening is a necessary component of these programs..$^{22}$ Nevertheless, clinicians practising in a setting where there are integrated staff-assisted systems may be more inclined to choose screening given that treatment is more likely to be effective in this setting.

\section{Other guidelines}

The current recommendation (to not routinely screen for depression in adults at average or increased risk of depression in primary care set-

Table 2: Summary of available recommendations on screening for depression in adults

\begin{tabular}{|c|c|c|c|}
\hline Organization & Risk assessment & Recommendation & Screening test \\
\hline $\begin{array}{l}\text { Canadian Task Force on } \\
\text { Preventive Health Care } \\
\text { (current) }\end{array}$ & No recommendation* & $\begin{array}{l}\text { - Recommend not routinely screening } \\
\text { adults at average risk in primary care } \\
\text { settings } \\
\text { - Recommend not routinely screening } \\
\text { subgroups of the population in primary } \\
\text { care settings who have characteristics that } \\
\text { may increase their risk of depression } \\
\text { (e.g., people with a family history of } \\
\text { depression or with chronic health problems) }\end{array}$ & No recommendation \\
\hline $\begin{array}{l}\text { Canadian Task Force on } \\
\text { Preventive Health Care } \\
(2005)^{14}\end{array}$ & No recommendation & $\begin{array}{l}\text { Recommend screening adults for } \\
\text { depression in primary care settings } \\
\text { with both feedback to the clinician } \\
\text { regarding depression status and a } \\
\text { system for managing treatment } \\
\text { (antidepressant medications and } \\
\text { psychotherapeutic interventions) }\end{array}$ & No recommendation \\
\hline $\begin{array}{l}\text { UK National Institute } \\
\text { for Health and Clinical } \\
\text { Excellence }- \text { adults }^{12}\end{array}$ & $\begin{array}{l}\text { - History of depression } \\
\text { - Chronic physical health problem with } \\
\text { associated functional impairment }\end{array}$ & $\begin{array}{l}\text { Recommend being alert to possible } \\
\text { depression }\end{array}$ & Whooley questionst \\
\hline $\begin{array}{l}\text { UK National Institute } \\
\text { for Health and Clinical } \\
\text { Excellence - perinatal } \\
\text { women }^{41}\end{array}$ & $\begin{array}{l}\text { - Past or present severe mental } \\
\text { illness (e.g., schizophrenia, bipolar } \\
\text { disorder, psychosis in the postnatal } \\
\text { period and severe depression) } \\
\text { - Previous treatment (including in- } \\
\text { patient care) by a psychiatrist or } \\
\text { specialist mental health team } \\
\text { - Family history of mental illness } \\
\text { during perinatal state }\end{array}$ & $\begin{array}{l}\text { - Recommend identifying possible } \\
\text { depression at a woman's first contact } \\
\text { with primary care, at her booking visit } \\
\text { [first prenatal visit] and postnatally } \\
\text { (usually at 4-6 wk and 3-4 mo) }\end{array}$ & $\begin{array}{l}\text { Whooley questions } \\
\text { plus help question } \neq\end{array}$ \\
\hline $\begin{array}{l}\text { UK National Institute } \\
\text { for Health and Clinical } \\
\text { Excellence - people } \\
\text { with chronic illnesses }\end{array}$ & $\begin{array}{l}\text { - History of depression } \\
\text { - Chronic physical health problem } \\
\text { with associated functional } \\
\text { impairment }\end{array}$ & $\begin{array}{l}\text { - Recommend being alert to possible } \\
\text { depression }\end{array}$ & Whooley questionst \\
\hline $\begin{array}{l}\text { US Preventive Services } \\
\text { Task Force }\end{array}$ & No recommendation & $\begin{array}{l}\text { - Recommend screening for depression } \\
\text { in adults in clinical practices that have } \\
\text { systems in place to assure accurate } \\
\text { diagnosis, effective treatment and } \\
\text { follow-up }\end{array}$ & No recommendation \\
\hline
\end{tabular}


tings) is a change from the 2005 task force guideline, which recommended screening adults for depression in primary care settings where integrated staff-assisted systems are available to manage treatment. The 2005 recommendation was based on an analysis of a literature review done in 2002 for the US Preventive Services Task Force, ${ }^{40}$ which showed that screening improved the accuracy of diagnosis of depression and that benefit was more likely in settings where screening was linked to effective followup and treatment. Many of the trials included in the 2002 literature review did not exclude people with prior or known depression, which may have overestimated the benefits of screening.

In contrast, the current task force recommendations place a higher value on the lack of evidence showing a direct benefit of screening for depression and place less value on indirect evidence and on trials that evaluated the merits of detecting and treating depression in integrated staff-assisted systems (Appendices 4, 5 and 6), especially because availability of integrated staff-assisted systems in Canada is varied. Of note, the updated (2009) systematic review for the US Preventive Services Task Force concluded that, although treatment of depression is more likely to be effective in integrated staffsupported systems, it is unclear whether screening for depression is a necessary component of these programs..$^{22}$

Table 2 provides a comparison between the current and previous task force guidelines,${ }^{14}$ as well as recommendations from other groups. ${ }^{12,13,41,42}$ Explanation for the differences in guidelines between countries may relate to different judgments about the quality of available evidence.

\section{Gaps in knowledge}

Better information is needed about the diagnostic accuracy of screening instruments for depression (especially in people with characteristics that may increase their risk for depression) and about the best way to screen for depression in primary care settings. High-quality randomized controlled trials with an unscreened control group that evaluate the effect of screening for depression on clinically relevant outcomes (e.g., sustained remission or depression-related mortality) should be a high priority, especially in populations with a higher baseline prevalence of depression. Future clinical trials should also report on the potential harms of screening, including labelling and stigma, falsepositive diagnoses and inappropriate treatment. In particular, such trials should carefully examine the implications of earlier detection in people who would be identified only through screening.

\section{Conclusion}

Our recommendations highlight the lack of evidence about the benefits and harms of routinely screening for depression in adults. In the absence of a demonstrated benefit of screening, and in consideration of the potential harms, we recommend not routinely screening for depression in primary care settings, either in adults at average risk or in those with characteristics that may increase their risk of depression. However, clinicians should be alert to the possibility of depression, especially in patients with characteristics that may increase their risk of depression, and should look for it when there are clinical clues, such as insomnia, low mood, anhedonia and suicidal thoughts.

\section{References}

1. Public Health Agency of Canada. Mood disorders. In: The human face of mental health and mental illness in Canada 2006. Ottawa (ON): The Agency; 2006. p. 57-70. Available: www.phac-aspc.gc .ca/publicat/human-humain06/index-eng.php (accessed 2012 Nov. 13).

2. American Psychiatric Association. Diagnostic and statistical manual of mental disorders. Fourth edition. Text revision. Washington (DC): The Association; 2000.

3. Patten SB, Lee RC. Describing the longitudinal course of major depression using Markov models: data integration across three national surveys. Popul Health Metr 2005;3:11.

4. Evans DL, Charney DS, Lewis L, et al. Mood disorders in the medically ill: scientific review and recommendations. Biol Psychiatry 2005;58:175-89.

5. Public Health Agency of Canada. The mental health and well-being of Aboriginal peoples in Canada. In: The human face of mental health and mental illness in Canada 2006. Ottawa (ON): The Agency; 2006. p.159-79. Available: www.phac-aspc.gc.ca/publicat /human-humain06/index-eng.php (accessed 2012 Nov. 13).

6. Vegas-López O, Blanco C, Keyes K, et al. Psychiatric disorders in pregnant and postpartum women in the United States. Arch Gen Psychiatry 2008;65:805-15 10.1001/archpsyc.65.7.805.

7. Public Health Agency of Canada. Problematic substance use. In: The human face of mental health and mental illness in Canada 2006. Ottawa (ON): The Agency; 2006. p.131-50. Available: www.phac-aspc.gc.ca/publicat/human-humain06/index-eng.php (accessed 2012 Nov. 13).

8. Public Health Agency of Canada. Suicidal behaviour. In: The human face of mental health and mental illness in Canada 2006. Ottawa (ON): The Agency; 2006. p.105-16. Available: www.phac-aspc.gc.ca/publicat/human-humain06/index-eng.php (accessed 2012 Nov. 13).

9. Scott KM, Von Korff M, Angermeyer MC, et al. Association of childhood adversities and early-onset mental disorders with adultonset chronic physical conditions. Arch Gen Psychiatry 2011;68: 838-44.

10. World Health Organization. Annex Table 3: Burden of disease in DALYs by cause, sex and mortality stratum in WHO regions, estimates for 2002. In: The World Health Report 2004. Geneva (Switzerland): The Organization; 2004. Available: www.who.int /whr/2004/annex/topic/en/annex_3_en.pdf (accessed 2013 Apr. 18).

11. Stephens T, Joubert N. The economic burden of mental health problems in Canada. Chronic Dis Can 2001;22:18-23.

12. US Preventive Services Task Force recommendation statement. Screening for depression in adults. Ann Intern Med 2009;151: 784-92.

13. National Collaborating Centre for Mental Health. Depression: the treatment and management of depression in adults (updated edition) [NICE Clinical Guidelines, no. 90]. Leicester (UK): British Psychological Society; 2009. Available: www.nice.org.uk/CG90 (accessed 2013 Apr. 18).

14. MacMillan HL, Patterson CJ, Wathen CN, et al. Screening for depression in primary care: recommendation statement from the Canadian Task Force on Preventive Health Care. CMAJ 2005; 172:33-5.

15. Canadian Task Force on Preventive Health Care. Procedure manual. Edmonton (AB): The Task Force; 2011. Available: 
http://canadiantaskforce.ca/methods/methods-manual (accessed 2013 Apr. 13).

16. Connor Gorber S, Singh H, Pottie K, et al. Process for guideline development by the reconstituted Canadian Task Force on Preventive Health Care. CMAJ 2012;184:1575-81.

17. Keshavarz H, Fitzpatrick-Lewis D, Streiner D, et al. Screening for depression: a summary of the evidence for the Canadian Task Force on Preventive Health Care. Hamilton (ON): McMaster Evidence Review and Synthesis Centre; 2012.

18. Schünemann H, Brozek J, Oxman A, editors. GRADE handbook for grading quality of evidence and strength of recommendations. Version 3.2 [updated March 2009]. GRADE Working Group; 2009

19. Patten SB, Juby H. A profile of clinical depression in Canada. Calgary (AB): Department of Community Health Sciences and Psychiatry, University of Calgary; 2008. Available: http://hdl .handle.net/1880/46327 (accessed 2013 Apr. 18)

20. Kaneko Y, Motohashi Y, Sasaki H, et al. Prevalence of depressive symptoms and related risk factors for depressive symptoms among elderly persons living in a rural Japanese community: a cross-sectional study. Community Ment Health J 2007:43:583-90.

21. Shah A. A replication of the relationship between elderly suicides rates and elderly dependency ratios: a cross-national study. J Inj Violence Res 2010;2:19-24.

22. O'Connor EA, Whitlock EP, Gaynes B, et al. Screening for depression in adults and older adults in primary care: an updated systematic review. Rockville (MD): Agency for Healthcare Research and Quality; 2009. [Evidence synthesis no. 75. AHRQ publication no. 10-05143-EF-1.] Available: www.ncbi .nlm.nih.gov/books/NBK36403/ (accessed 2013 Apr. 18).

23. Gilbody S, Sheldon T, House A. Screening and case-finding instruments for depression: a meta-analysis. CMAJ 2008;178:997-1003.

24. Pompili M, Serafini G, Del Casale A, et al. Improving adherence in mood disorders: the struggle against relapse, recurrence and suicide risk. Expert Rev Neurother 2009;9:985-1004.

25. Thombs BD, Arthurs E, El-Baalbaki G, et al. Risk of bias from inclusion of patients who already have diagnosis of or are undergoing treatment for depression in diagnostic accuracy studies of screening tools for depression: systematic review. BMJ 2011; 343:d4825 10.1136/bmj.d4825.

26. Elkin I, Shea MT, Watkins JT, et al. Treatment of depression collaborative research program: general effectiveness of treatments. Arch Gen Psychiatry 1989;46:971-82.

27. Paykel ES, Hollyman JA, Freeling P, et al. Predictors of therapeutic benefit from amitriptyline in mild depression: a general practice placebo-controlled trial. J Affect Disord 1988;14:83-95.

28. Van Voorhees BW, Cooper LA, Rost MK, et al. Primary care patients with depression are less accepting of treatment than those seen by mental health specialists. J Gen Intern Med 2003; 18:991-1000.

29. Mojtabai R, Olfson M. National patterns in antidepressant treatment by psychiatrists and general medical providers: results from the national comorbidity survey replication. J Clin Psychiatry 2008;69:1064-74

30. Klinkman MS, Coyne JC, Gallo S, et al. False positives, false negatives and the validity of the diagnosis of major depression in primary care. Arch Fam Med 1998;7:451-61.

31. Coyne JC, Schwenk TL, Fechner-Bates S. Nondetection of depression by primary care physicians reconsidered. Gen Hosp Psychiatry 1995; 17:3-12

32. Leigh B, Milgrom J. Acceptability of antenatal screening for depression in routine antenatal care. Aust J Adv Nurs 2007;24:14-8.

33. Allen K, Cull A, Sharpe M. Diagnosing major depression in medical outpatients: acceptability of telephone interviews. J Psychosom Res 2003;55:385-7.

34. Kocsis JH, Leon AC, Markowitz JC, et al. Patient preference as a moderator of outcome for chronic forms of major depressive disorder treated with nefazodone, cognitive behavioral analysis system of psychotherapy, or their combination. J Clin Psychiatry 2009;70:354-61.

35. Kwan BM, Dimidjian S, Rizvi SL. Treatment preference, engagement, and clinical improvement in pharmacotherapy versus psychotherapy for depression. Behav Res Ther 2010;48:799-804.

36. Mergl R, Henkel V, Allgaier A-K, et al. Are treatment preferences relevant in response to serotonergic antidepressants and cognitive-behavioral therapy in depressed primary care patients? Results from a randomized controlled trial including a patients' choice arm. Psychother Psychosom 2011;80:39-47.

37. Swift JK, Callahan JL. The impact of client treatment preferences on outcome: a meta-analysis. J Clin Psychol 2009;65:368-81

38. Valenstein M, Vijan S, Zeber JE, et al. The cost-utility of screening for depression in primary care. Ann Intern Med 2001;134:345-60.

39. Patten SB. A framework for describing the impact of antidepressant medications on population health status. Pharmacoepidemiol Drug Saf 2002;11:549-59.
40. Pignone MP, Gaynes BN, Rushton JL, et al. Screening for depression in adults: a summary of the evidence for the U.S. Preventive Services Task Force. Ann Intern Med 2002;136:765-76.

41. National Collaborating Centre for Mental Health. Antenatal and postnatal mental health. The NICE guideline on clinical management and service guidance [NICE Clinical Guidelines, no. 45]. London (UK): British Psychological Society and Royal College of Psychiatrists; 2007.

42. National Collaborating Centre for Mental Health. Depression in adults with a chronic physical health problem. Treatment and management [NICE Clinical Guidelines, no 91]. London (UK): National Institute for Health and Clinical Excellence; 2009.

Guidelines writing group: Michel Joffres, Alejandra Jaramillo, James Dickinson, Gabriela Lewin, Kevin Pottie, Elizabeth Shaw, Sarah Connor Gorber and Marcello Tonelli.

Affiliations: From the Faculty of Health Sciences (Joffres), Simon Fraser University, Burnaby, BC; the Public Health Agency of Canada (Connor Gorber), Ottawa, Ont.; the Department of Family Medicine (Pottie, Lewin), University of Ottawa, Ottawa, Ont.; the Departments of Family Medicine and Community Health Sciences (Dickinson), University of Calgary, Calgary, Alta.; the Department of Family Medicine (Shaw), McMaster University, Hamilton, Ont.; and the Division of Nephrology (Tonelli, Jaramillo), Department of Medicine, University of Alberta, Edmonton, Alta

Contributors: Michel Joffres, Alejandra Jaramillo, James Dickinson, Gabriela Lewin, Kevin Pottie, Elizabeth Shaw, Sarah Connor Gorber and Marcello Tonelli contributed substantially to the conception and design of this work. All of the authors contributed substantially to the interpretation of the findings. Alejandra Jaramillo, Michel Joffres and Marcello Tonelli drafted the article with assistance from the rest of the guidelines writing group, and all of the authors gave final approval of the version submitted for publication.

Endorsement: This guideline has been endorsed by the College of Family Physicians of Canada.

Funding: Funding for the Canadian Task Force on Preventive Health Care is provided by the Public Health Agency of Canada and the Canadian Institutes of Health Research. The views of the funding bodies have not influenced the content of the guideline; competing interests have been recorded and addressed. The views expressed in this article are those of the authors and do not represent those of the Public Health Agency of Canada.

Acknowledgements: The authors acknowledge members of the Evidence Review and Synthesis Centre research team who conducted the systematic review upon which these recommendations were based, the staff at the Task Force Office of the Public Health Agency of Canada, and the organizational reviewers and peer reviewers whose thoughtful comments helped to improve the quality of this manuscript (Lori-Ann Smith, Public Health Agency of Canada; Barbara Sérandour, Statistics Canada; Victoria Smye, UBC School of Nursing; Francine Knoops, Mental Health Commission of Canada; Howard Chodos, Mental Health Commission of Canada; Christina Bancej, Public Health Agency of Canada; Barbara Foster, Health Canada; Lorna Martin, Canadian Counselling and Psychotherapy Association; Lisa Ashley, Canadian Nurses Association; Margaret Czesak, Health Canada; John Higenbottam, Chronic Disease Prevention Alliance of Canada; Gilles Plourde, Health Canada; Peter J. Bieling, McMaster University; Douglas M. Maurer, Madigan Army Medical Center; Gordon H. Guyatt, McMaster University; Nathalie Gendron, Canadian Institutes of Health Research; Brett D. Thombs, McGill University; Victoria Winterton, College of Family Physicians of Canada; Scott B. Patten, University of Calgary; and Kami Kandola, Council of Chief Medical Officers of Health).

The appendices for this article are available at www.cmaj.ca/lookup/suppl/doi:10.1503/cmaj $.130403 /-/ D C 1$ 